\title{
INTERSEX(ES) AND INFORMED CONSENT: HOW PHYSICIANS' RHETORIC CONSTRAINS CHOICE
}

\begin{abstract}
When a child is born with ambiguous genitalia it is declared a psychosocial emergency, and the policy first proposed by John Money (Johns Hopkins University) and adapted by the American Academy of Pediatrics (and more broadly accepted in Canada, the U.K., and Europe) requires determination of underlying condition(s), selection of gender, surgical intervention, and a commitment by all parties to accept the "real sex" of the patient, all no later than 18-24 months, preferably earlier. Ethicists have recently questioned this protocol on several grounds: lack of medical necessity, violation of informed consent, uncertainty of standards of success, among others. This suggests that the faults in the protocol can be addressed and improved. Through a rhetorical approach informed by Perelman/Olbrechts-Tyteca, the disciplinary pathologization and reconstruction of the body are explored as incidents of constraining rhetoric that enact their persuasion upon the body of intersexed children. This essay shows that the presumptions, judgments, values, and presuppositions brought by the physician to the identification, diagnosis, and curative procedures create a network of constraints that exclude alternative possibilities. The result is a situation wherein parents, physicians, and intersexed patients have "no choice" but to accept the medical treatment guidelines.
\end{abstract}

KEY WORDS: informed consent, intersex, "optimal-gender policy,” Perelman/OlbrechtsTyteca, rhetoric and the frameworks of argumentation

Nursie: You almost were a little boy, my cherry pip.

Queen Elizabeth: What?

Nursie: Yea. Out you popped out of your Mummy's tumkin, and everyone shouted, "It's a boy! It's a boy!" And then someone said, "But he hasn't a winkle!" And then I said, "A boy without a winkle? God be praised, its a miracle! A boy without a winkle!" And then Sir Thomas More pointed out that a boy without a winkle is a girl ...

- "Bells," Black Adder II

\section{INTRODUCTION}

The roots of the current controversy concerning the medical management paradigm for the treatment of intersexed children, referred to as the "optimal-gender policy," can be traced back to the foundation of the Intersex Society of North America (ISNA). Motivated by the article in Sciences magazine published by Anne Fausto-Sterling, "The Five

Theoretical Medicine 25: 21-49, 2004.

(C) 2004 Kluwer Academic Publishers. Printed in the Netherlands. 
Sexes: Why Male and Female Are Not Enough."2 ISNA founder Cheryl Chase has called for the cessation of all surgeries upon infants until long-term, follow-up studies of their effects were performed and their results released. ${ }^{3}$ In the intervening years, the "optimal-gender policy," first proposed by John Money of Johns Hopkins University ${ }^{4}$ and premised upon the assumption that children are psychosexually neutral at birth, has come under increasing fire by medical ethicists and patients. The bulk of the criticism follows along two significant argumentative trajectories, each of which is developed within the context of the ethics of "informed consent."

First, physicians and parents routinely avoid giving forthright information to the intersexed patient, both as a result of paternalistic desire to avoid inflicting confusion and pain but more directly as a result of the guidance to give only "age-appropriate explanation." Criticism of this practice has been widespread, with numerous first-person accounts of patients reflecting a shared experience of confusion and resentment arising from the secrecy and silence of parents and physicians. ${ }^{6}$ As a result, several recent changes to the guidelines have advocated that parents and patients be kept well informed of the condition. ${ }^{7}$ It is not clear, however, that physicians have broadly adapted these practices of complete candor, ${ }^{8}$ so this issue continues to generate controversy.

Second, many have begun to question the standards by which to judge "successful" outcomes of the protocol. ${ }^{9}$ With respect to surgical outcomes, physicians and patients have begun to question the subjective and cosmetic standards upon which they are uniformly declared a success. ${ }^{10}$ Additionally, initial success rates do not translate into long-term positive outcomes, ${ }^{11}$ nor do standards of sexual function and patient experience play a role. ${ }^{12}$ Furthermore, no large-scale, long-term follow up research has been done with respect to the success of the overall purpose of the guidelines, namely the happiness and comfort with which the patient has come to accept his/her assigned gender. ${ }^{13}$ Coupled with research undermining the working assumption of John Money regarding the psychosexual neutrality of children at birth, ${ }^{14}$ the basis and success of guidelines have been questioned, forcing some in the physician community to take another look. ${ }^{15}$

In toto, these criticisms not only put in question the scientific basis upon which the procedures are exercised (and justified), but also seriously question whether the principle of "informed consent" has been legally and ethically applied. ${ }^{16}$ If information is neither freely shared nor is information ready-to-hand, how can one suggest that decisions made by parents on behalf of their children can be "informed consent"? ${ }^{17}$ On the basis of this argument, many have called for a moratorium on genital surgery until 
long-term outcomes of both surgery and the guidelines have been made and carefully assessed. ${ }^{18}$

While in agreement with these critical approaches, this essay seeks to bring another methodological approach to the issue. I wish to focus upon what the rhetorical theorists Chaim Perelman and Lucie OlbrechtsTyteca ${ }^{19}$ have called the "starting points of argumentation": the values, facts, truths, presumptions, and judgment that govern the selection and representation of data prior to their use in specific strategies of argumentation. This approach is part of a broader strategy, which is elsewhere called a "rhetoric of power," 20 and positions the physician-patient exchange within contexts of (1) institutionally sanctioned patterns of behavior, (2) disciplinary habits that constrain the exchange, (3) the assumptions of authority brought to the exchange by both participants, and (4) the communal and societal contexts informing this exchange.

For the purposes of this essay, we will concentrate upon the insights that rhetorical criticism brings to the issue of "informed consent." We will focus upon the argumentative presumptions and dynamics at work informing the context of the physician-parent(-patient) decision-making process. Through specific, sanctioned modes of reasoning, authoritative models of interpretation, accepted facts and dominant values, medicine creates a rhetorical context that limits and constrains parent-patient decision making during the process of diagnosis and treatment of intersexed patients. We will come to see how these "frameworks of argumentation" function within the physician-patient encounter. What will become clear is that the implicit and fundamental purpose of diagnosis and treatment is persuasion, enacted through rhetorical means whereby the body of the patient becomes an object held under a hermeneutics of suspicion, requiring (through the assumed premises of argumentation) medical intervention as a necessary conclusion. The result is a circumstance that constrains the decisions of both parents and physicians, such that ethical agency of the patient (or the patient's representatives), even under circumstances of "informed consent," can never be granted.

\section{THE CURRENT MEDICAL PROTOCOL}

In order to pursue our analysis, it is necessary to outline the means by which the condition is recognized and the stages undertaken by physicians to determine a diagnosis and suggest courses of treatment. The psychosocial management of intersexed children is a protocol based upon the research of John Money of the Psychosocial Research Unit of the Johns Hopkins Medical Center. The American Academy of Pediatrics has 
codified it in its Policy Statement RE9958. Other national organizations in Europe have published similar guidelines, and recent articles from the Middle East and India suggest a worldwide acceptance of its practices. Additionally, many reference articles and even patient guidelines continue to advocate its employment. Although controversy has recently been acknowledged, discussions continue to assume the guidelines developed by Money and Jane and John Hampson as the guiding structure and principles whose practices need validation and improving. By considering carefully the principles and practices advocated by the "optimal-gender" policy, we can situate the argumentative choices made by physicians when presenting treatment options to parents.

The context within which treatment of intersexuality takes place is, of course, the context of identifiable cases of intersexuality. This context is difficult to ascertain for two reasons: First, there is the question of the frequency of intersexuality itself. Second, there is the question of how intersexuality comes to be identified at the time of birth.

The question of frequency regarding intersexuality is a question of the definition of the term itself. Contributing to the confusion about its limits and constraints are several factors, all of which are quite fluid and indeterminate. First, the frequencies of the various conditions ${ }^{21}$ that lead to a diagnosis of intersexed birth are themselves highly variable. Secondly, it is difficult to decide what to count as "sexed ambiguity," since many of the conditions leading to an intersexed diagnosis do not necessarily always lead to genital ambiguity. Thirdly, variations in frequency are found between populations and geographical locations, making it difficult to know how large a sample is necessary to adjust for potential bias. Finally, history and culture determine the identification of intersex(es), causing variation in the criteria of what constitutes "male" and "female" and the significance of their differences.

Nevertheless, given all the caveats mentioned above, researchers have recently suggested a frequency of 1.7 intersexed births per $100,{ }^{22}$ with surgery "required" in 1 in 2,000 births. ${ }^{23}$ In the United States and Europe alone, this would suggest that tens of thousands of intersexed children are born each year, with an average of between five and ten surgeries performed per day throughout the Western/European world. This frequency is greater than that of cystic fibrosis ( 1 in 2,500 "Caucasian" births), ${ }^{24}$ Down syndrome ( 1 in $\left.800-1000\right)^{25}$ or Albino births (one in $17,000),{ }^{26}$ conditions with comparatively much broader public awareness.

If we accept these numbers, what is suggestive is the difference between frequency of conditions leading to the diagnosis of intersexuality and the frequency of genital ambiguity that would lead to surgical interven- 
tion. Among possible explanations for this difference, one must carefully consider the (subjective and) culturally predetermined bases upon which a physician comes to identify genitalia as ambiguous. In any case, what chronologically takes place is not the identification of a given condition leading to a diagnosis of intersexuality (although certain forms of prenatal testing may contribute in the future to just such identification). Instead, what causes the eventual identification of intersexuality is the perceptual confusion of the attending physician regarding the morphology of the genitals of the newborn. It is only after the doctor finds himself or herself confused about the genitals that tests take place to identify the underlying condition. ${ }^{27}$

In 1955, John Money (together with the Hampsons) first proposed the guidelines currently in use by physicians throughout most of Europe and adopted by schools of medicine throughout the world. ${ }^{28}$ (1) Gender assignment should go to the gender most likely to maintain reproductivity, good sexual function, normal-looking external genitalia and stable gender identity; (2) the decision should be made as early as possible, within the newborn period, but no later than 18-24 months, with initial genital construction surgeries performed within this timeframe; (3) parents and professionals should be fully committed to the final decision about gender assignment and the subsequent gender of rearing, should inform the child with age-appropriate explanations about their situation, and should follow up with the administration of gender-appropriate hormones at the onset of puberty. The assumption is that with consistent and constant rhetorical and medical reinforcement the child will never question their assigned gender identity and will integrate into society as a "normal" and "healthy" girl or boy.

The process of gender assignment works as follows. Upon the birth of an "ambiguously gendered" child, the attending physician declares a "social emergency" 29 and a team (which can consist of the original referring physician, pediatric endocrinologist, pediatric urologists, geneticist, and possibly a psychologist, psychiatrist or a psychoendocrinologist ${ }^{30}$ is called together to diagnose the conditions underlying the ambiguity, to ascertain the body's "true" gender, and to decide upon the gender assignment and gender of rearing. Gender assignment is determined according to the following guidelines: (1) "Genetic females should always be raised as females, preserving reproductive potential, regardless of how severely the patients are virilized." 31 (2) "In the genetic male, however, the gender of assignment is based on the infant's anatomy, predominantly the size of the phallus." ${ }^{32}$ If the child is XX and can be fertile, she will be assigned "female." This can include, in cases of "virilization," surgeries to reduce 
the size of the phallus to a more acceptable size (physicians specify 0.2 to 0.9 centimeters as an "appropriate" "clitoral" size for a newborn, based upon a table of "normal" sizes), ${ }^{33}$ and to create a "functioning" "vagina" (defined as one that can allow the entry of a "normal sized" penis without pain when an adult). On the other hand, if the child is XY, then the test for determining the gender assignment shifts from reproductivity to sexual performance, as defined by appropriate "penile" length and the ability to stand up to urinate. "Appropriate" length is 2.5 to 4.5 centimeters for a newborn. ${ }^{34}$ If the "penis" is below $2.5 \mathrm{~cm}$, or the child has a hypospadic "penis," the child has traditionally been assigned a female gender. ${ }^{35}$ This is due to the fact that, generally speaking, the surgeons have had a difficult time fashioning a "penis" that can successfully live up to the social standards required of it. ${ }^{36}$ Lately, however, anecdotal evidence suggests that raising children with a micropenis, ${ }^{37}$ penoscrotal hypospadias or cloacal extrophy ${ }^{38}$ as males is beginning to take hold, ${ }^{39}$ due mainly to published reports of successful heterosexual practices on the part of men with micropenises. ${ }^{40}$ Overall, however, feminizing surgery is more prevalent ${ }^{41}$ and among infants with clitoromegaly, cliteroplastic surgery is still widely performed and advocated. ${ }^{42}$

Throughout this period of diagnosis and decision, physicians are careful to offer explanations to the parents, and later to the developing child, such that they will not undermine the certainty of the assignment. The rhetorical representation of the diagnosis seeks to reinforce through naturalizing rhetoric the belief in the two-sex system, and the commitment to "one-body, one-sex" is maintained throughout the curative program. This representational consistency is recognized as vital to the success of the acceptance of the assignment by both parents and child.

Its practice commences with the initial consultation, wherein the physicians approach the parents by stating that the child really does have a gendered identity but that the genitals and gonads are incomplete, and the "true sex" of the child has to be more clearly investigated. Accordingly, the physician is directed to state that the gender of the child is not yet "finished," and their procedures will help to "correct" and "complete" this development.

It is helpful to examine the child in the presence of the parents to demonstrate the precise abnormalities of genital development, emphasizing that the genitalia of both sexes develop from the same primordial fetal structures, that both incomplete development or overdevelopment of the external genitalia can occur, and that the abnormal appearance can be corrected and the child raised as a boy or girl as appropriate. ${ }^{43}$

During this time physicians generally counsel parents not to assign a sex to the affected newborn, nor to name the child. If asked, the parents 
are counseled to avoid gender pronouns when referring to the child, using phrases like "our baby," "our child," etc. It is also important to use "neutral terms such as baby, gonad and phallus instead of sex-specific terms like boy or testes or ovaries and penis or clitoris." 44 Only after the "true sex" has been chosen are the parents told of the results of the investigation. The name is then chosen, the birth record filled out, and the surgeries are scheduled. Integrity of the gender identity system and the determination of the gender are thereby maintained in the hands of the physicians, and consistency of this message plays a key role in the assignment process.

The most controversial aspect of the original protocol is the ensuing commitment to the assignment as reinforced through intentional deflection on the part of both physicians and parents. "[A]ccurate patho-physiological explanations are not appropriate and medical honesty at any price is of no benefit to the patient." 45 "Discretion" becomes a fundamental aspect of the guidelines, since the guidelines depend upon clear, congruent, and consistent messages being sent to the parents and the child so as not to create confusion. ${ }^{46}$ Success of the adoption of the gender assignment is premised upon the intersexed individual not knowing they are intersexed. Truth telling within this protocol is seen as threatening the very success of the protocol, ${ }^{47}$ since it would mean informing the parent and the child/young adult that the gender of the child was in question. ${ }^{48}$

What is clearly ascertainable with the help of this summary is that the fundamental operating presumption of the guidelines is the belief in the necessity of the binary sex system. This presumption represents the constraining hegemony of culturally mandated gender systems over the medical field. Commitment to the belief in "one-sex, one-body," "twoand-only-two sexes" places physicians in a position of functioning as social gatekeepers whose skills are used to "fix" the patient's genitals. This results in a profound disconnect within the medical field, as it requires researchers and practitioners to ignore fundamental, empirical evidence of human sex formation: namely, that human sexual morphology (phenotype, karyotype, identity, practice) is multitudinous and that this multiplicity falls within the range of statistical normativity for variability ${ }^{49}$ According to a certain epistemological standard of empirical observation and cognitive assessment, one typically embraced and promulgated by medical research and pedagogy, intersexuality is indeed a "normal" physiological event among human beings. However, from a cultural perspective, it is unacceptable, thereby impacting upon the medical investigation, identification, and treatment.

The gate-keeping function that medicine performs in cases of intersexuality places medicine in the position of pathologizing the site of 
the body, rendering the body suspicious when held up against culturally mandated ideals. This is not something new to medicine (consider, e.g., the marketing practices on behalf of plastic surgery), ${ }^{50}$ but it does get to the heart of an important ethical imperative for physicians in these cases: How and when does "difference" mandate medical intervention, and at what point does difference become "pathological"?

More specifically, since intersexuality is not a medical risk, but rather a psychosocial event, the question of sexual "difference" per se is clearly not one that requires a medical response. It is therefore necessary to ascertain the means by which physicians turn a psychosocial emergency into a medical emergency requiring surgical, hormonal, perhaps even psychological intervention. How do physicians convince families (and in some cases patients) that the bodies of their intersexed children "need" fixing, and do these means offer real choices to them?

\section{THE STARTING POINTS OF ARGUMENTATION}

A whole literature exists on the sociology of the physician-patient relationship and the social construction of diagnosis. ${ }^{51}$ Additionally, recent literature on the social construction of the body, with emphasis upon the performative nature of sex and sexuality, ${ }^{52}$ has provided an important theoretical backdrop against which certain criticisms leveled against the "optimal-gender policy" can be understood. The rhetorical approach taken here contributes to these discussions by focusing upon the ways in which certain values, presumptions, and judgments make their impact upon the inventional processes of medical identification, diagnosis, and treatment with respect to intersexuality. It does so by identifying their role in the foundations upon which the physician can represent the case to the parents.

The approach offered here is distinct from ethical or philosophical approaches, insofar as it does not seek to clarify or argue about fundamental terms or specific propositional content of presumed universal values. Rather than asking how a specific medical activity may or may not conform to a specific ethical principle, a rhetorical approach proposes to view the rhetorical dynamics of exchange and assess their outcomes according to the principles presumed by those enacting medical decisions. In this way, a rhetorical approach is complementary to that of sociologists of medicine, but differs from it by focusing upon the argumentational aspects of medical discourse and investigation, viewing them as practices meant to secure conviction and commitment to warranted actions. It considers medical knowledges and practices as examples of persuasion, grounded upon authorized habits of invention, arrangement and delivery. 
Methodologically, we will turn to the theory of argumentation introduced by Perelman/Olbrechts-Tyteca. Their model makes available the discursive, extra-linguistic, pre- and post-performance constraints and strategies of argumentation and persuasion at work in any given symbolic encounter between a rhetor and an audience. By focusing upon the starting points of argumentation, and considering the material dimensions of communication, we can take account not just of the multiple intentionalities (physician, parent, society, patient), nor only the multiple contextualities (medical, legal, socio-cultural), but also and particularly the disciplinary habits of the production of medical knowledge.

In other words, we will view the physician-patient relationship as more than simply identifying a diagnosis and implementing a cure. We will consider the inventional means by which symptoms and diagnoses are identified, the presumptions governing this process, the argumentative efforts at securing conviction to follow through on certain procedures. We will view these within the context of institutionalized preferences that sanction certain ways of viewing and representing medical practices. We will consider the effects of these rhetorical dynamics upon both patients and physicians as active participants in the production of knowledge in contexts of persuasion.

\section{RHETORIC IN THE MEDICAL MANAGEMENT OF INTERSEXED CHILDREN}

It is clear that rhetoric suffuses any doctor-patient exchange. Most physicians would probably view the process of diagnosis as an objective series of questions and decisions based upon empirical evidence for the purpose of "truth seeking." Our approach, however, understands this exchange as an inventional process within a disciplinary context constraining the use and function of certain evidences, governed by specific values that give weight to certain sets of data and certain outcomes over other sets of data and outcomes. Diagnosis processes, curing protocols, and results assessments are artful exchanges governed by the introduction at key moments of certain values.

Although there are many different ways in which we might pursue a rhetorical approach to the medical management of the intersex(es), at this point we will concentrate only upon seven fields of analysis. These fields focus upon the selection and presentation of data, the assumptions and judgments at work prior to the analysis and diagnosis of the condition, the function of values shaping the presentation of the curative procedures, as well as the role and function of different audiences in the shaping of 
the discourse between physicians, physicians and parents, and physicians and patients. These fields of focus will help us understand the disciplinary constraints at work shaping and generating knowledge of intersex(es), but also constraining the choices available to physicians and parents when working together to medically manage the intersexed child.

(1) The selection of data to be considered relevant to identifying and determining gender. A scientific discipline draws data from a body of knowledge familiar to those in the discipline. Nevertheless, scientific debates concern themselves with the choices made within the discipline and how these choices constitute this body of knowledge: "[C]hoice of the facts deemed relevant, choice of hypotheses, choice of the theories that should be confronted with facts, choice of the actual elements that constitute facts." ${ }^{53}$ The method of each science implies such a choice and the history of that field reveals its changing adherence to certain choices made over others.

The data that are chosen by the physician to determine gender identity are external genital morphology and aesthetics. No other data are initially considered. These data, under most cases, seem sufficient, insofar as the genitals appear according to expectation and conform to a presumed sex dichotomy of two and only two available sexes, with the body displaying only one of those sexes.

It is only after a body presents data that do not conform to these expectations that other data are considered. These additional data are derived from internal sources of the body in an effort to "draw out" the body's "true gender." Only at this point are chromosomes, gonadal formation, internal phenotype, electrolyte levels, and hormones considered. Genital appearance becomes just one of several data that then enter into the discussion, all of which focus on the body as a source of hidden, internal data in need of discovery and interpretation.

What does not enter into the discussion are other factors just as determinative for the identification of the intersexed child's gender: the success of the psychosexual protocol with respect to the unquestioning adoption of assigned gender; the standards by which to judge this success; long-term follow-up research on those who have undergone treatment; success of specific surgical procedures with respect to genital construction. In other words, the data that are chosen for consideration by the physicians have not included the results of their decisions or the outcomes of the "optimal-gender" policy. Instead, they include only those data that presume the policy's successful results. As such, the selection of data forecloses other possible approaches, but does so without 
providing the necessary evidentiary warrants. The result for the patient is an experimental procedure made available as the only possible "solution" to "fix" the pathologized body.

(2) The presumption of the "self-evidential" quality of sex-gender "facts." With respect to gender identification, it is part of the process of gender assignment that everyone knows what they are looking for: there is a penis, scrotum, testicles, and their presence signals a biological "given" that a person with these is a "male." There is also a clitoris (distinct from a penis), labia (distinct from a scrotum), and vagina (that leads to the uterus), and a person having these is clearly and biologically identified as "female." It is "self-evident" that there exist two and only two sexes, that a body must have only one sex associated with it, and that the genitalia function as the determinate of gender identity.

Setting aside the issue of "ambiguous genitalia" and the implications these may have upon the "self-evidential" nature of the male/female binary gender paradigm, one important factor is usually overlooked: If genital clarity is vital to gender identity formation, how is transgenderism explained? The "optimal-gender" policy is based upon a theory of gender formation that requires construction of genitalia: if the genitals can send clear, unambiguous signals to the child and parents, then the child will adapt him/herself to those signals and accept the gender being communicated by him/her. This overlooks an important datum: there are individuals who were assigned a particular gender at birth, premised upon what were for the physician at the time of birth unquestionably clear gender markers, but whose identity do not conform to that assignment. This datum would suggest a different source or standard for determining gender identity.

The "optimal-gender" theory assumes a reductionistic relationship between genital presentation and gender identity that has neither been demonstrated nor considers the very clear evidence of transgenderism to the contrary.

(3) The selection of accepted methods of interpreting these data. The methods for interpreting the data of gender identity include, first and foremost, looking at the genitals. If there is a penis and testicles, then the individual is "male." If there is no penis, then the individual is "female." It is only when this method cannot be clearly applied that other methods enter in.

Historically, physicians have responded to genital ambiguity in two ways: First, in the face of the variety of physiological sexual formation, physicians developed a classification system to help sort the variety of 
data and their interpretation. Drawing from nineteenth century taxonomies, at least three classes of "abnormal" gender variations exist: "female pseudo-hermaphrodite" (a "true female" whose anatomy has similarities to "males," thus leading to a "false" diagnosis of "hermaphroditism"), "male pseudo-hermaphrodite" (a "true male" whose anatomical features "look" hermaphroditic, insofar as they may look "female"), and a "true hermaphrodite" (a person with evidence of both testicular and ovarian tissues). These labels continue to serve as a methodological basis upon which to sort out the various indicators and conditions of intersexuality, and to place the intersexed child into a "known" spectrum of conditions and their results.

Second, however, this classification system no longer functions to determine sexual assignment. That responsibility is left to the medical team to determine based upon specific socio-somatic guidelines premised upon heterosexual norms of gender function: Can a "female pseudohermaphrodite" become a "successful" woman with the appropriately sized clitoris, the potential for fertility, and a vagina that allows penetration by a penis? Can a "male pseudo-hermaphrodite" become a "successful" man with a penis that functions according to social mandates?

The method used by physicians to assign gender devolves back upon the genitals and how well they live up to the social and cultural expectations required of them, and not upon the physical indicators "discovered" through the process of diagnosis.

It is important also to consider the interesting role the physical body plays during this phase of "data interpretation." What is typically thought of as the foundational and unassailable determinate of gender identity becomes problematized and pathologized if its signals are seen as "ambiguous."

Here is where a hermeneutics of suspicion enters into the question of identity. Once the genital body loses its status as self-evidential datum by displaying genitals that do not conform to other presumptions, it is declared "faulty," "abnormal," or "incomplete," thereby ruling out its standing in the decision-making enterprise. Other aspects of the body, those that are not obvious, those that are hidden to all but the specialists, come to the fore. Once these have been "discovered," the "truth" has been produced, and the genital body is forced to conform to that "hidden" truth.

The body, once the fundamental determinate of gender identity, is now disciplined into conformity by surgical means according to cultural standards. Only a surgically altered body can be "natural" and "normal," and hence accepted into society. 
(4) The presumption that a statistical norm is normative for gender. For physicians, there exists a presumption that what constitutes the "normal" ought to be normative for determining gender identity. Indeed, one could argue that a statistical norm defines the genitals: a clitoris is "not" a clitoris until it conforms to the statistical norms. Until that time, it can be "mistaken" for a penis, or is viewed as "monstrous." Similarly, a "penis" isn't a "penis," until it achieves a certain length. The physician team will set about to determine the size of a newborn's penis to ascertain whether it will be able to meet certain expectations regarding size and length. The application of hormones (e.g., hCG testing) to determine penis growth is performed, and if successful, the penis is allowed to stay; otherwise, clitoroplasty is performed.

What is clear is that the size of the phallus does not represent an immediate health risk or danger to the child. Indeed, only two conditions (certain Prader levels associated with Congenital Adrenal Hyperplasia [CAH] and gonadal dysgenesis) underlying intersexuality do put the patient at risk. Nevertheless, statistical deviation from the norm with respect to genital formation (the size and shape of a "penis" or "clitoris"), gonadal formation (the presence of two, similarly structured gonads that are clearly either ovaries or testes, but not both), hormone affects upon the body and the "secondary sex factors" it displays, become a cause for intervention: a statistical infrequency becomes a "medically necessary" intervention.

Rather than intersexuality leading the physician to question "normative" function of the statistical "norm" and to reconsider what is "normal" about human gender formation, the body of the intersex(es) is made to conform to the statistical "norm," to confirm it. Otherwise it resides outside the "norm" as a deviating and developmentally suspect body.

(5) The role of social values, and indeed a hierarchy of values, when determining gender. Values play a fundamental role in the determination of gender. Several values are easily identifiable: the scientific value of "discovering" the underlying conditions of intersexuality; the scientific value of identifying a fundamental determinate of gender; the statistical value of genital appearance; the social value of gender identity; the implicit values in the rhetoric of categorizing and labeling certain physiological conditions associated with intersexuality; the implicit values of heterosexuality in the construction of these categories and their labels,${ }^{54}$ technological values at work in ascertaining "successful" surgical outcomes. Medicine is not the objective pursuit of truth, devoid of values and premised upon demonstrative reasoning. Medicine, as a human disci- 
pline, is informed by disciplinary-specific values that constrain and shape knowledge formation.

Elsewhere it would be fruitful to explore the relationship of the physician-patient exchange with respect to the broader cultural context shaping this exchange. ${ }^{55}$ For the moment, it is important simply to point out that values, while an unavoidable element in medicine, also shift and change. As the history of medicine shows us, there is no "once and for all" value that overrides all others in the field of medicine. The certain values shift according to location and history. Often, it is a question of a "hierarchy of values" that a group's identity (or a philosophical/ethical system's identity, or an "era" of a discipline's history) can perhaps best be described. Everyone can agree that "health" is a value worthy of the pursuit of medicine. What becomes difficult to do, however, is to define what one means by "health," since the act of concrete enactment of a universal value causes certain practices and their justifications to take precedence over others, according to socio-cultural and historical context.

For the physician deciding the gender assignment of an intersexed child, the conflict arises between the sacred value of "do no harm" and the social value of "full integration into society." The one value asserts an individual-level, case-by-case purview, while the other demands commitment to the values of the broader social group. With respect to the situation of an intersexed child, it is clear that social values have overridden all other considerations in the discussion.

Consider, for example, the case of CAH children. The "virilizing" effect of androgens upon the developing fetus presents a child whose genitals "look" "male." If the child is born in Europe or in the United States, medical practice is to assess the fertility potential of the ovaries, and if adult fertility is possible, to operate upon the body of the child in order to construct a "female" body type. There are various reasons given for this, but whatever the specific reasons, it is clear that the value of "female" reproductivity (assuming a heterosexual matrix) is clearly at work as the most important for determining the gender assignment.

If, however, the child is born in, for example, Saudi Arabia, medical management is to declare the child as "male," and to avoid performing surgeries upon "him." Here, the cultural cachet of male offspring overrides the value of potential fertility. A "son" has been born, and the doctor will not insist upon constructing out of "him" a "daughter," nor would the family. ${ }^{56}$ Instead, a treatment protocol that ensures the continuing health of the $\mathrm{CAH}$ child will be implemented, and the child will return home to the family without surgical reconstruction. 
The former situation plays up two interesting aspects of intersex management: (a) the determination of "male" or "female" gender assignments cannot be justified as a "purely" medically or biologically-founded one, but is clearly a socio-rhetorical construct whose purpose is to create a convincing replication of a normatively sanctioned body; and (b) even children diagnosed with $\mathrm{CAH}$, which carries with it a potential health risk-factor, can be managed without surgical gender reassignment.

Nevertheless, the values of the West require adherence to a gender ideology that demands conformity to a two-sexed system, with the correlate that one body must have one, and only one sex. It is this social value that overrides all others in the medical treatment of the intersexed.

(6) The role of audiences during the discussion of determination. With respect to the "optimal-gender" policy, it is clear that information shared with patients and family members is shaped according to the intended audience. Physicians will speak with other physicians and specialists, to the exclusion of the parents of the intersexed child, in ways that maintain disciplinarity, such as, for example, the use of highly specialized vocabulary regarding diagnostic techniques, their results, and the technical/ surgical options. The purpose of such is to maintain knowledge within the hands of a few and to shift the terms of the discussion in ways that maintain the validity of the "optimal-gender" policy, and the physician's authoritative role in it as arbiter of gender identity and social gatekeeper. ${ }^{57}$

Another whole approach is taken to the parents who are taught, through specific phrases and gestures, a rudimentary form of embryology. This is done for several reasons: (a) to help the parent to "see" the ambiguity facing the physician; (b) to help the parent locate the difficulty upon the body of the infant; (c) to maintain the rigid male/female dichotomy; (d) to allow the physician to pursue the hidden "truth" within the body; (e) thereby to place the body in suspension, and give into the hands of the physician the ability to complete the body's arrested development. To quote one article, "parents must reach the same decision regarding sex assignment as the experts who have educated them." 58 In this way, the body is placed at the disposal of the physician's role as "healer," and the parents are addressed in a way that helps them to recognize this role, accept its diagnosis on the basis of specialized knowledge and skill, and thereby maintain the authority of the physician as the one to direct treatment.

Still another approach is brought to the child, whose role has traditionally been to accept, without question, the body as it has been surgically altered to conform to the child's assigned gender. Analysis 
of success, and of the larger issue of gender role markers, is premised upon binary, and therefore heterosexual, standards of behavior and the child's ability to perform according to these standards. The newborn, even the prepubescent child is structurally not allowed an active role in the decision making process regarding the surgical interventions made upon the body. The patient is, in theory, if not also in practice, an experiment in the success of the protocol to enforce a binary sex-role system.

(7) The goal of the protocol to "convince" the intersexed individual, parents, and society that the individual is, indeed, what they have been assigned to be. The success of the method does not lie in overcoming the obstacles to health that place the intersexed child medically at risk. As we have seen, the only "risk" to the child (aside from, e.g., CAH electrolyte imbalance, or AIS testicular cancer) is social, and it is with respect to this basis alone that "success" is sought. Careful use of language, and the commitment to pursue a course of total conviction regarding the validity of the gender assignment, lays the foundation upon which the intersexed child can make a transition into society without questioning the assignment.

This issue here isn't one of "origins." It is true that the protocol is premised upon certain working assumptions of "nurture" overcoming "nature." It is also true that others in the debate argue for the importance of hormones in imprinting a gendered identity structure upon the brain. Ultimately, however, the issue is not where gender comes from. The issue is how successfully the intersexed person can be convinced of his/her gender assignment, how convincingly the patient conforms to certain societal expectations of gendered behavior, and how successfully he or she thereby integrates into society. Persuasion, not origins, is the fundamental issue. Interestingly, the goal of persuasion is not to increase public awareness of intersexuality, nor to question the fundamental values of gender binarism. It is to reinforce a two-sexed system.

\section{PATHOLOGY AND THE ELIMINATION OF AGENCY}

With respect to our rhetorical analysis of the judgments, assumptions, values, facts, and presumptions and their impact upon the representation of, knowledge about, and argumentative goals for intersexual intervention, the results of our analysis suggest the following insights:

(1) Under the "optimal-gender policy," the body of the intersexed child undergoes a profound evidentiary shift. At first the body is the justificatory ground for clinical testing, providing an "empirical" basis for 
intervention whose truth can be brought out by means of testing. Once this "truth" is discovered, however, the body is then held as an invalid source of evidence regarding the truth of its sexuality: it is viewed under a hermeneutics of suspicion until it can be surgically normalized, after which it must be continually maintained. This isolates the patient as a pathological object, sets the patient in a social and medical zone of liminality, and creates a hierarchy of power between physician and patient wherein decision-making agency is given over into the hands of the physician who treats the body as an object in need of constant surveillance and care.

(2) The values at work in the decision making process pathologize the body on the basis of external genital markers, and not on the basis of the condition underlying the "ambiguous" genitals. This results in shifting the purpose of the medical intervention from an issue of "medicine" to that solely premised upon the "need" for social gate-keeping, since the purpose of surgery is to enact non-ambiguity premised upon a cultural-historical value of "two and only two sexes, one body/one sex." The result is the justification of radical surgical intervention on the body of the child, not for the sake addressing any physiological issue detrimental to the safety of the child, but for the sake of maintaining a culturally and historically derived gender ideology.

(3) The decision regarding gender assignment is premised upon social standards and statistical norms, indicating the prevalence of a fear of difference at work both in the pathologizing of the patient's condition, as well as in the determination of the assignment. The decision is also premised upon a social value hierarchy that places female fertility on the one hand, and penile erectile function and length on the other, at the top of the scale. The role of the concept of the "normal" and its function within medical practices (not limited to the care of the intersexed patient) is to create an ideal derived from cultural and historical values against which the body is to be judged. Medicine becomes an idealist enterprise, reinforced through the rhetoric of "deviation," and presenting itself as the solution for those "problems" that do not meet the ideal.

(4) The pathology of the body is rendered through the rhetorical performance of the physician. The representation and demonstration of (i.e., parental consultation and education about) "ambiguous" genitalia are efforts not only to justify viewing the birth of the child as a "social emergency." More importantly, they seek to justify a series of interven- 
tions whose sole purpose is to eliminate the cosmetic indicators that are the cause of the ambiguity. At no point has it been demonstrated that the gender indicators are a cause of either medical or psychosocial "disease" (accepting, for the moment, the distinction between these terms). Instead, the underlying conditions are treated as incidental to the overwhelming "need" to surgically alter the child to conform to norms of genital appearance. It is the rhetoric employed by the physician that pathologizes the genitalia, not the condition behind the ambiguity.

In light of these insights, the question that confronts those who are agitating for a change in the management guidelines is whether and how their reforms might fundamentally alter the position under which the intersexed patient and their parents are rhetorically placed. Even if the patient and family are fully informed of the condition and the results (good or bad) of the proposed medical treatment paradigm, can consent ever be granted given the rhetoric of suspicion under which the body of the patient is placed? No matter what "improvements" may be made, it is the argumentative representation of the intersexed condition as nonnormal/non-normative that constrains the choices made by both parents and physicians. Indeed, the very means by which inquiry and discovery are performed in medicine with respect to intersexuality predetermine the role of the patient. It is not just representation that is the issue, it is the very nature of the means of inquiry that constrain the medico-rhetorical context.

As such, even if all current criticisms raised by patient advocacy groups and medical ethicists will be met, for example, through improved surgical practices, patient follow up, counseling and support, etc., the intersexed patient by definition remains under a hermeneutics of suspicion, a boundary violation in need of constant surveillance.

While some medical ethicists have questioned the notion of "autonomy" and its usefulness in ethical deliberations in medicine, ${ }^{59}$ others have also wondered whether consent can ever be obtained by a patient in a context where physicians are assigned duties and patients are granted rights. To hold a right either prohibits or obliges action on the part of others, but does not grant moral agency. "A right confers an option, and as such is quite different from a duty which imposes a requirement, the enactment or denial of which constitutes the moment of moral agency." 60

For the intersexed patient, however, it is the rhetorical judgments, presumptions, facts, and values governing the very concept and representation of intersexuality itself that circumvent the assignment of either duties 
or rights to the patient. The rhetoric of pathology fundamentally constrains the autonomy and freedom of the parents and patients by denying the natural state of the patient its social and physiological legitimacy. Under the "optimal-gender policy," the pathological state of the intersex(ed) patient generates a subject whose fundamental nature falls outside the realm of social subjectivity, and hence agency. While it is possible for parents and their children to decide not to pursue a medical course of treatment, this choice is made in the face of a specific rhetorical enterprise, supported by social sanctions, directed against the ambiguously gendered patient whose very body renders the issue of subjectivity questionable unless and until the body is made to conform.

Deeply embedded within the medical management protocol is a distrust of the intersexed body. It is a distrust grounded upon deep-seated assumptions of sex-gender formativity and naturalized values of scientific inquiry and social roles. It is reinforced through the selection and presentation of data and facts and the appropriate methods of their interpretation. It is a distrust communicated to parents and patients through a rhetoric ultimately directed toward providing the means for a convincing performance of gender within the binary paradigm.

The body is rendered suspect, the condition is presented to the parents in terms of deviation and pathology, medical research and intervention is presented as the cure, the intended audience is parents and observers, the result is an inevitable (rhetorically tautological) conclusion: an enforced conformity that marks its strategies of power upon the suspicious body of the intersex(es) itself.

\section{ACKNOWLEDGEMENTS}

I would like to acknowledge support of the Alexander von HumboldtStiftung for funding research leading to this publication. Thanks also goes to the Interfakultäres Zentrum für Ethik in den Wissenschaften of the University of Tübingen, its MitarbeiterInnen, and especially Prof. Dr. EveMarie Engels, its Sprecherin. Particular gratitude must be extended to Prof. Dr. Dietmar Mieth and Dr. Regina Ammicht-Quinn of the Catholic Faculty at Tübingen, and Prof. Dr. Hille Haker of Harvard Divinity for their support of this project. 


\section{NOTES}

1 H.F.L. Meyer-Bahlburg, "Gender Assignment in Intersexuality," Journal of the Psychology of Human Sex 10 (1998): 1-21; cf. also idem, "Gender Identity Development in Intersex Patients," Child and Adolescent Psychiatric Clinic North America 2 (1993): 501-512; idem, "Gender and Sexuality in Classic Congenital Adrenal Hyperplasia," Endocrinology and Metabolism Clinics of North America 30/1 (2001): 155-171; idem, "Gender Assignment and Reassignment in Intersexuality: Controversies, Data, and Guidelines for Research," in S.A. Zderic, D.A. Canning, M. C. Carr, and H. Snyder, eds. Pediatric Gender Assignment: A Critical Reappraisal (Dordrecht: Kluwer Academic/Plenum Publishers, 2002), pp. 199-223; and American Academy of Pediatrics RE9958, "Evaluation of the Newborn With Developmental Anomalies of the External Genitalia," Policy Statement 106/1 (2001).

2 A. Fausto-Sterling, "The Five Sexes: Why Male and Female are Not Enough," The Sciences (March/April 1993): 20-25.

3 Cf. "Recommendations for Treatment," developed by the ISNA, available at $<$ www.isna.org $>$.

4 J. Money, J.G. Hampson, and J.L. Hampson, "Hermaphroditism: Recommendations Concerning Assignment of Sex, Change of Sex, and Psychological Management," Bulletin of Johns Hopkins Hospital 97(1955): 284-300; idem, "Imprinting and the Establishment of Gender Role," Archives of Neurology and Psychiatry 77 (1957): 333-336. See also J. Money, Sex Errors of the Body and Related Syndromes: A Guide to Counseling Children, Adolescents, and Their Families, 2nd edn. (Baltimore: Paul H. Brookes Publishing, 1994); J. Money and A. Ehrhardt, Man and Woman, Boy and Girl (Baltimore: The Johns Hopkins University Press, 1972).

5 AAP Policy Statement RE 9958, cited in n. 1, above.

6 Besides the many first-person narratives in the collection of essays by A. Dreger, Intersex in the Age of Ethics (Hagerstown: University Publishing Group, 1999), see also $<$ www.isna.org/library/bibonline.html $>$ for links to many essays available on line.

7 Cf., e.g., AAP Policy Statement RE9958, cited in n. 1, above: "Because of the remaining uncertainties with regard to the long-term psychological and physical aspects of treatment among these patients, ongoing counseling of the parents and the affected child is advisable." C. Migeon, A. Wisniewski, and J. Gearhart, Syndromes of Abnormal Sex Differentiation: A Guide for Patients and Their Families (Baltimore: The Johns Hopkins Children's Center, 2001), has a section on "Psychological Treatment" and a section on "Support Group Contact Information." Recent publications by H.F.L. Meyer-Bahlburg also note the value of counseling; cf. "Gender Assignment and Reassignment in Intersexuality," cited in $\mathrm{n} .1$, above.

8 E. Nussbaum, "A Question of Gender," Discover (2000): 92-99; R. Marion, "The Curse of the Garcias," Discover (2000): 42-44; A. Yronwode, "Intersex Individuals Dispute Wisdom of Surgery on Infants," Synapse: University of California at San Francisco Medical School (1999).

9 Cf. A. Fausto-Sterling, Sexing the Body: Gender Politics and the Construction of Sexuality (New York: Basic Books, 2000), pp. 82-83 (Table 4.1), pp. 88-91 (Table 4.2).

10 See "Draft Statement of the British Association of Paediatric Surgeons (BAPS)

Working Group on the Surgical Management of Children Born with Ambiguous Genitalia" (July 2001), Appendix: Clitoral Surgery, available at $<$ http://www.baps.org.uk/documents/ Intersex\%20statement.htm $>$. 
11 N.K. Alizai, D.F. Thomas, R.J. Lilford, A.G. Batchelor, and N. Johnson, "Feminizing Genitoplasty for Congenital Adrenal Hyperplasia: What Happens at Puberty?" Journal of Urology 161/5 (1999): 1592-1593. S.M. Creighton, C.L. Minto, and S.J. Steele, "Objective Cosmetic and Anatomical Outcomes at Adolescence of Feminising Surgery for Ambiguous Genitalia Done in Childhood," Lancet 358/9276 (2001): 124-125.

12 L.S. Baskin, A. Erol, Y.W. Li, W.H. Liu, E. Kruzrock, and G.R. Cunha, "Anatomical Studies of the Human Clitoris," Journal of Urology 162/3.2 (1999): 1015-1020, has determined that the current model of innervation underlying modern clitoral recessions is wrong. See also B. May, M. Boyle, and D. Grant, "A Comparative Study of Sexual Experiences," Journal of Health Psychology 1/4 (1996): 479-492, and R.W. Dittman, M.E. Kappes, and M.H. Kappes, "Sexual Behaviour in Adolescent and Adult Females with Congenital Adrenal Hyperplasia," Pscyhoneuroendocrinology 17/2-3 (1992): 153-170, for long-term follow up studies on sexual practices of patients having undergone clitoroplastic surgery.

13 The North American Task Force on Intersexuality, founded in 2000 by pediatric urologist Ian Aaronson of the Medical University of South Carolina in Charleston, is the first concerted, systematic effort by the medical community to look at all the clinical data and gather all the information available regarding clinical responses to genital ambiguity and their long-term outcomes.

14 Cf., e.g., W. Reiner, "Case Study: Sex Reassignment in a Teenage Girl," Journal of the American Academy of Child and Adolescent Psychiatry 35/6 (1996): 799-803. S. Holmse, J.M. Kirk, M.O. Savage, and R.S. Kirby, "Surgical Reinforcement of Gender Identity in Adolescent Intersex Patients," Urologia Internationalis 48 (1992): 430-433. M. Diamond and H.K. Sigmundson, "Sex Reassignment at Birth: Long-Term Review and Clinical Implications," Archives of Pediatric and Adolescent Medicine 151 (1997): 298304.

15 M. Diamond and H.K. Sigmundson, "Sex Reassignment at Birth: Long-term Review and Clinical Implications," Archives of Pediatric and Adolescent Medicine 151 (1997): 298-304. However, note S. Bradley, G. Oliver, A. Chernick, and K. Zucker, "Experiment of Nurture: Ablatio Penis at 2 Months, Sex Reassignment at 7 Months, and a Psychosexual Follow-up in Young Adulthood," Pediatrics 107/1 (1998), electronic article 9, http://pediatrics.aappublications.org/. The provenance of this article has recently come under question. Cf. J. Colapinto, As Nature Made Him: The Boy Who Was Raised As A Girl (New York: Perennial Press, 2001). See also, however, the discussion in F.M.E. Slijper, "Long-Term Psychological Evaluation of Intersex Children," Archive of Sexual Behavior 27/2 (1998): 125-144.

16 H. Beh and M. Diamond, "An Emerging Ethical and Medical Dilemma: Should Physicians Perform Sex Assignment Surgery on Infants with Ambiguous Genitalia?" Michigan Journal of Gender and Law 7/1 (2000): 1-63; K. Kipnis and M. Diamond, "Pediatric Ethics and the Surgical Assignment of Sex," Journal of Clinical Ethics 9/4 (1998): 398-410.

17 K.-K. Ford, “'First, Do No Harm' - The Fiction of Legal Parental Consent to Genital-Normalizing Surgery on Intersexed Infants," Yale Law and Policy Review 19 (2001): 469-488. Ford questions the legal exceptions to the three criteria (informed consent, voluntariness, and competency) of informed consent that provide the basis for medical intervention: emergent condition and parental "substituted judgment." Cases of intersexuality do not meet the legal standards for either exception. 
18 See also S. Creighton and C. Minto, "Editorial: Managing Intersex," British Journal of Medicine 323 (2001): 1264-1265; Kipnis and Diamond, "Pediatric Ethics and the Surgical Assignment of Sex," cited in n. 16, above.

19 C. Perelman and L. Olbrechts-Tyteca, The New Rhetoric: A Treatise on Argumentation (University of Notre Dame Press, 1969).

20 J.D.H. Amador, Academic Constraints in Rhetorical Criticism of the New Testament: An Introduction to a Rhetoric of Power (Sheffield: Sheffield Academic Press, 1999).

21 F.A. Conte and M.A. Grumbach, "Pathogenesis, Classification, Diagnosis, and Treatment of Anomalies of Sex," in L. De Groot, ed. Endocrinology (New York: Saunders, 1989), pp. 1810-1847.

22 M. Blackless, A. Charuvastra, A. Derryck, A. Fausto-Sterling, K. Lauzanne, and E. Lee, "How Sexually Dimorphic are We? Review and Synthesis," American Journal of Human Biology 12 (2000): 151-166.

23 A. Fausto-Sterling, "The Five Sexes, Revisited," The Sciences (July/August 2000): $18-23$.

24 Cf. http://www.phd.msu.edu/DNA/cf_fact.html from Michigan State University DNA Diagnostic Program.

25 Cf. http://www.ndss.org/aboutds/aboutds.html\#incidence of the National Down Syndrome Society.

26 Cf. http://www.cbc.umn.edu/iac/facts.htm\#whatis of the International Albinism Center of the University of Minnesota.

27 Cf., e.g., J. Hutcheson, "Ambiguous Genitalia and Intersexuality," eMedicine Journal. Pediatrics, Urology. <www.emedicine.com/ped/topic1492.htm>.

28 Cf. also R. Rosenfield, A. Lucky, and T. Allen, "The Diagnosis and Treatment of Intersex," Current Problems in Pediatrics 10/7 (1980): 1-66; K. Glassberg, "Gender Assignment in Newborn Male Pseudohermaphrodites," Urology Clinics of North America 7/2 (1980): 409-421.

29 AAP RE9958, cited in n. 1, above; Hutcheson et al., "Ambiguous Genitalia and Intersexuality," cited in n. 27 , above.

30 Cf., e.g., "Draft Statement of the BAPS Working Party," 1.2(b), cited in n. 10, above; see also Hutcheson, "Ambiguous Genitalia and Intersexuality," Treatment: Consultations, cited in n. 27, above; Migeon et al. Syndromes of Abnormal Sex Differentiation, "Endocrine Treatment," cited in n. 7.

31 Compare also AAP RE9958, cited in n. 1, above: "All female infants virilized because of CAH or maternal androgens are potentially fertile and should therefore be raised as girls."

32 Quotes from P.K. Donahoe, D.M. Powell, and M.M. Lee, "Clinical Management of Intersex Abnormalities," Current Problems in Surgery 28/8 (1991): 517-579: 527. Compare also AAP RE9958, cited in n. 1: "The size of the phallus and its potential to develop at puberty into a sexually functional penis are of paramount importance when one is considering male sex of rearing."

33 S. Oberfeld, A. Mondok, F. Shahrivah, J.F. Klein, and L.S. Levine, "Clitoral Size in Full-Term Infants," American Journal of Perinatology 6/4 (1989): 453-454.

34 "A micropenis is ... defined as having a stretched length of less than two and a half standard deviations below the mean for age or stage of sexual development." J. Riley and C. Wodehouse, "Small Penis and the Male Sexual Role," Journal of Urology 142 (1989): 569-571. For a newborn, that means a minimum acceptable length of 2.5 centimeters. 
35 "Never assign a baby to be reared, and to surgical and hormonal therapy, as a boy, unless the phallic structure, hypospadiac or otherwise, is neonatally of at least the same caliber as that of same-aged males with small-average penises." J. Money, "Psychological Counseling: Hermaphroditism," in L. Gardner, ed. Endocrine and Genetic Diseases of Childhood and Adolescence (Philadelphia: WB Saunders, 1975), pp. 609-618, at p. 610.

36 Cf. L. Tiefer, "The Medicalization of Impotence - Normalizing Phallocentrism," Gender and Society 8/3 (1994): 363-377.

37 Reilly and Woodhouse, "Small Penis and the Male Sexual Role," cited in n. 34, above.

38 W. Reiner, "Sex Assignment in the Neonate with Intersex or Inadequate Genitalia," Archives of Pediatrics and Adolescent Medicine 151/10 (1997): 1044-1045.

39 M. Hendricks, "Into the Hands of Babes," Johns Hopkins Magazine (2000). <www. jhu.edu/ jhumag/0900web/babes.html>

40 A.P. van Seters and A.K. Slob, "Mutually Gratifying Heterosexual Relationship with Micropenis of Husband," Journal of Sex \& Marital Therapy 14/2 (1988): 98-107.

41 Cf. the now infamous quote, "you can dig a hole, but you can't build a pole," referring to the reasons for the prevalence of feminizing genitoplastic. M. Hendrick, "Is it a Boy or a Girl?" Johns Hopkins Magazine (1993): 10-16.

42 Cf. F.M.E. Slijper, S.L.S. Drop, J.C. Molenaar, and R.J. Scholtmaijer, "Neonates with Abnormal Genital Development Assigned the Female Sex: Parent Counseling," Journal of Sex Education and Therapy 20/1 (1994): 9-17; M. Rohatgi, "Intersex Disorders: An Approach to Surgical Management," Indian Journal of Pediatrics 59 (1992): 523-530.

43 AAP RE9958, cited in n. 1, above. See also Migeon et al. Syndrome of Abnormal Sex Differentiation, cited in $\mathrm{n} .7$, above, which provides a detailed but accessible primer on "normal" and "disordered" pathways of sex differentiation.

44 Migeon, Syndromes of Abnormal Sex Differentiation, "Endocrine Treatment," cited in n. 7, above; cf. also AAP RE9958, cited in n. 1, above.

45 M. Forest, "Inborn Errors of Testosterone Biosynthesis," Pediatric and Adolescent Endocrinology 8 (1981): 133-155.

46 L. Peris, "Congenital Adrenal Hyperplasia Producing Female Hermaphroditism with Phallic Urethra," Obstetrics and Gynecology 16/2 (1960): 156-166; F.M.E. Slijper et al., "Neonates with Abnormal Genital Development," 10-11, 14, cited in n. 42, above; P. Lee, T. Mazur, R. Danish, J. Amrhein, R.M. Blizzard, J. Money, and C.L. Migeon, "Micropenis. I. Criteria, Etiologies and Classification,” Johns Hopkins Medical Journal 146 (1980): 156163; Forest, "Inborn Errors of Testosterone Biosynthesis," cited in n. 45, above.

47 A. Natarajan, "Medical Ethics and Truth Telling in the Case of Androgen Insensitivity Syndrome," Canadian Medical Association Journal 154/4 (1996): 568-570. This essay was written while the author was a student, and it was the second-place winner of the 1995 Logie Medical Ethics Contest. Interestingly, since becoming a practitioner the author has distanced herself from this position, and now advocates full disclosure (with caveats) and cooperation. The essay has proven an embarrassment to the CMAJ, although the Editors stood by their decision to award her the Logie Medical Ethics prize.

48 Recently, however, published guidelines by the AAP and Johns Hopkins have emphasized the need for physicians to turn parents and patients to resources and support groups to help them understand the full implications of intersexed patient. It is not clear, however, to what extent this shift has made an impact upon clinical, daily patient-physician interaction, as physicians continue to report a hesitation to be completely candid with patients or their families. Cf. Marion, "The Curse of the Garcias" and Nussbaum, "A Question of Gender," both cited in $n .8$, above. 
49 L. McCullough, "The Ethics of Gender Reassignment," presentation at 1999 Pediatric Gender Reassignment Conference: A Critical Reappraisal (Wyndham-Anatole Hotel, Dallas, TX, April 30, 1999).

50 Cf. A. Balsamo, "On the Cutting Edge: Cosmetic Surgery and the Technological Production of the Gendered Body," Camera Obscura 28 (1992): 207-237.

51 An example of such literature includes: P. Wright and A. Treacher, eds., The Problem of Medical Knowledge: Examining the Social Construction of Medicine (Edinburgh: Edinburgh University Press, 1982); P. Brown, ed., Perspectives in Medical Sociology, 2nd edn. (Prospect Heights: Waveland, 1996), pp. 92-122; E. Armstrong, "Diagnosing Moral Disorder: The Discovery and Evolution of Fetal Alcohol Syndrome," Social Science and Medicine 47/12 (1998): 2024-2042; H. Arksey, "Expert and Lay Participation in the Construction of Medical Knowledge," Sociology of Health and Illness 16/4 (1994): 448-468; P. Conrad, "Medicalization and Social Control," Annual Review of Sociology 18 (1992): 209-232; B.J. Good and M.-J. DelVecchio Good, “'Learning Medicine': The Constructing of Medical Knowledge at Harvard Medical School," in S. Lindenbaum and M. Lock, eds. Knowledge, Power, and Practice: The Anthropology of Medicine and Everyday Life (Berkeley: University of California Press, 1993), pp. 81-107. S. Hirschauer, "The Manufacture of Bodies in Surgery," Social Studies of Science 21/2 (1991): 279-319. M. Berg and G. Bowker, "The Multiple Bodies of the Medical Record: Toward a Sociology of an Artifact," The Sociological Quarterly 38/3 (1997): 513-537.

52 The most important theorist of the performativity of gender is J. Butler. See her Gender Trouble: Feminism and the Subversion of Identity (New York: Routledge, 1990); Bodies That Matter: On the Discursive Limits of "Sex" (New York: Routledge, 1993); The Psychic Life of Power: Theories on Subjection (Palo Alto: Stanford University Press, 1997). S. Kessler and W. McKenna, Gender: An Ethnomethodological Approach (Chicago, IL: University of Chicago Press, 1978) can also be mentioned here, as can be the collection of essays assembled by A. Kroker and M. Kroker, eds., The Last Sex: Feminism and Outlaw Bodies (New York: St. Martin's Press, 2001); The Hysterical Male: New Feminist Theory (New York: St. Martin's Press, 1991); Body Invaders: Panic Sex in America (New York: St. Martin's Press, 1987). See also E. Grosz, Volatile Bodies: Toward a Corporeal Feminism (Bloomington, IN: Indiana University Press, 1994); Space, Time and Perversions: Essays on the Politics of Bodies (New York: Routledge, 1995); J. Price and M. Shildrick, Feminist Theory and the Body: A Reader (New York: Routledge, 1999); S. Bordo, Unbearable Weight: Feminism, Western Culture and the Body (Berkeley, CA: University of California Press, 1995); K. Davis, Embodied Practices: Feminist Perspectives on the Body (Thousand Oaks: Sage Press, 1997); A. Balsamo, Technologies of the Gendered Body: Reading Cyborg Women (Durham: Duke University Press, 1997).

53 Perelman and Olbrechts-Tyteca, The New Rhetoric, p. 116, cited in n. 19, above.

54 See A. Dreger, Hermaphrodites and the Medical Invention of Sex (Cambridge: Harvard University Press, 2000), pp. 110-138, and Fausto-Sterling, Sexing the Body, pp. 71-73, cited in n. 9, above.

55 J.D. Hester, "Rhetoric of the Medical Management of Intersexed Children: New Insights into 'Disease,' 'Illness,' 'Curing' and 'Healing,' ' Genders 38 (Fall 2003). <www. genders.org >

56 S. Taha, "Male Pseudohermaphroditism: Factors Determining the Gender of Rearing in Saudi Arabia," Urology 43 (1994): 370-374. See also H. Al-Attia, "Gender Identity and Role in a Pedigree of Arabs with Intersex due to 5 Alpha Reductase-2 Deficiency," Pscyhoneuroendocrinology 21 (1996): 651-657. 
57 Cf. J. Money, "Psychological Counseling: Hermaphrodism," in L.I. Gardner, ed. Endocrine and Genetic Diseases of Childhood and Adolescence (Philadelphia: W. B. Saunders, 1975), pp. 609-618. See especially p. 613 where he states that "medical terminology has a special layman's magic in such a context; it is final and authoritative and closes the issue."

58 H. Meyers-Seifer and N. Charest, "Diagnosis and Management of Patients with Ambiguous Genitalia," Seminars in Perinatology 16 (1992): 332-339, at 338.

59 Cf., e.g., D.M. Hester, Community as Healing (Lanham, MD: Rowan \& Littlefield, 2001).

60 M. Schildreck, Leaky Bodies and Boundaries: Feminism, Postmodernism and (Bio)ethics (London: Routledge, 1997), p. 72.

\section{REFERENCES}

Al-Attia, H. "Gender Identity and Role in a Pedigree of Arabs with Intersex due to 5 Alpha Reductase-2 Deficiency.” Pscyhoneuroendocrinology 21 (1996): 651-657.

Alizai, N.K., D.F. Thomas, R.J. Lilford, A.G. Batchelor, and N. Johnson. "Feminizing Genitoplasty for Congenital Adrenal Hyperplasia: What Happens at Puberty?" Journal of Urology 161/5 (1999): 1592-1593.

Amador, J.D.H. Academic Constraints in Rhetorical Criticism of the New Testament: An Introduction to a Rhetoric of Power. Sheffield: Sheffield Academic Press, 1999.

American Academy of Pediatrics. RE9958, "Evaluation of the Newborn With Developmental Anomalies of the External Genitalia." Policy Statement 106/1 (2001).

Arksey, H. "Expert and Lay Participation in the Construction of Medical Knowledge." Sociology of Health and Illness 16/4 (1994): 448-468.

Armstrong, E. "Diagnosing Moral Disorder: The Discovery and Evolution of Fetal Alcohol Syndrome." Social Science and Medicine 47/12 (1998): 2024-2042.

Balsamo, A. "On the Cutting Edge: Cosmetic Surgery and the Technological Production of the Gendered Body." Camera Obscura 28 (1992): 207-237.

Balsamo, A. Technologies of the Gendered Body: Reading Cyborg Women. Durham: Duke University Press, 1997.

Baskin, L.S., A. Erol, Y.W. Li, W.H. Liu, E. Kruzrock, and G.R. Cunha. "Anatomical Studies of the Human Clitoris.” Journal of Urology 162/3.2 (1999): 1015-1020.

Beh, H. and M. Diamond. "An Emerging Ethical and Medical Dilemma: Should Physicians Perform Sex Assignment Surgery on Infants with Ambiguous Genitalia?" Michigan Journal of Gender and Law 7/1 (2000): 1-63.

Berg, M. and G. Bowker. "The Multiple Bodies of the Medical Record: Toward a Sociology of an Artifact." The Sociological Quarterly 38/3 (1997): 513-537.

Blackless, M., A. Charuvastra, A. Derryck, A. Fausto-Sterling, K. Lauzanne, and E. Lee. "How Sexually Dimorphic are We? Review and Synthesis." American Journal of Human Biology 12 (2000): 151-166.

Bordo, S. Unbearable Weight: Feminism, Western Culture and the Body. Berkeley: University of California Press, 1995.

Bradley, S., G. Oliver, A. Chernick, and K. Zucker. "Experiment of Nurture: Ablatio Penis at 2 Months, Sex Reassignment at 7 Months, and a Psychosexual Follow-up in Young Adulthood." Pediatrics 107/1 (1998), electronic article 9. http://pediatrics. aappublications.org/. 
British Association of Paediatric Surgeons. "Draft Statement of the British Association of Paediatric Surgeons (BAPS) Working Group on the Surgical Management of Children Born with Ambiguous Genitalia" (July 2001). www.baps.org.uk/documents/ Intersex\%20statement.htm.

Brown, P., ed. Perspectives in Medical Sociology, 2nd edn. Prospect Heights: Waveland, 1996.

Butler, J. Bodies That Matter: On the Discursive Limits of "Sex." New York: Routledge, 1993.

Butler, J. Gender Trouble: Feminism and the Subversion of Identity. New York: Routledge, 1990.

Butler, J. The Psychic Life of Power: Theories on Subjection. Palo Alto: Stanford University Press, 1997.

Colapinto, J. As Nature Made Him: The Boy Who Was Raised As A Girl. New York: Perennial Press, 2001.

Conrad, P. "Medicalization and Social Control." Annual Review of Sociology 18 (1992): 209-232.

Conte, F.A. and M. A. Grumbach. "Pathogenesis, Classification, Diagnosis, and Treatment of Anomalies of Sex." In Endocrinology. Edited by L. De Groot. New York: Saunders, 1989, pp. 1810-1847.

Creighton, S. and C. Minto. "Editorial: Managing Intersex." British Journal of Medicine 323 (2001): 1264-1265.

Creighton, S.M., C.L. Minto, and S.J. Steele. "Objective Cosmetic and Anatomical Outcomes at Adolescence of Feminising Surgery for Ambiguous Genitalia Done in Childhood." Lancet 358/9276 (2001): 124-125.

Davis, K. Embodied Practices: Feminist Perspectives on the Body. Thousand Oaks: Sage Press, 1997.

Diamond, M. and H.K. Sigmundson. "Sex Reassignment at Birth: Long-Term Review and Clinical Implications." Archives of Pediatric and Adolescent Medicine 151 (1997): 298304.

Diamond, M. and H.K. Sigmundson. "Sex Reassignment at Birth: Long-Term Review and Clinical Implications." Archives of Pediatric and Adolescent Medicine 151 (1997): 298304.

Dittman, R.W., M.E. Kappes, and M.H. Kappes. "Sexual Behaviour in Adolescent and Adult Females with Congenital Adrenal Hyperplasia." Pscyhoneuroendocrinology 17/23 (1992): 153-170.

Donahoe, P.K., D.M. Powell, and M.M. Lee. "Clinical Management of Intersex Abnormalities." Current Problems in Surgery 28/8 (1991): 517-79.

Dreger, A. Hermaphrodites and the Medical Invention of Sex. Cambridge: Harvard University Press, 2000.

Dreger, A., ed. Intersex in the Age of Ethics. Hagerstown: University Publishing Group, 1999.

Fausto-Sterling, A. “The Five Sexes: Why Male and Female are Not Enough.” The Sciences (March/April 1993): 20-25.

Fausto-Sterling, A. "The Five Sexes, Revisited.” The Sciences (July/August 2000): 18-23.

Fausto-Sterling, A. Sexing the Body: Gender Politics and the Construction of Sexuality. New York: Basic Books, 2000. 
Ford, K.-K. “' 'First, Do No Harm' - The Fiction of Legal Parental Consent to GenitalNormalizing Surgery on Intersexed Infants." Yale Law and Policy Review 19 (2001): 469-488.

Forest, M. "Inborn Errors of Testosterone Biosynthesis." Pediatric and Adolescent Endocrinology 8 (1981): 133-155.

Glassberg, K. "Gender Assignment in Newborn Male Pseudohermaphrodites." Urology Clinics of North America 7/2 (1980): 409-421.

Good, P.J. and M.-J. DelVecchio Good. "'Learning Medicine': The Constructing of Medical Knowledge at Harvard Medical School." In Knowledge, Power, and Practice: The Anthropology of Medicine and Everyday Life. Edited by S. Lindenbaum and M. Lock. Berkeley: University of California Press, 1993, pp. 81-107.

Grosz, E. Space, Time and Perversions: Essays on the Politics of Bodies. New York: Routledge, 1995.

Grosz, E. Volatile Bodies: Toward a Corporeal Feminism. Bloomington: Indiana University Press, 1994.

Hendricks, M. "Is it a Boy or a Girl?" Johns Hopkins Magazine (1993): 10-16.

Hendricks, M. "Into the Hands of Babes." Johns Hopkins Magazine (2000). www.jhu. edu/ jhumag/0900web/babes.html.

Hester, D.M. Community as Healing. Lanham: Rowan \& Littlefield, 2001.

Hester, J.D. "Rhetoric of the Medical Management of Intersexed Children," Genders (Fall 2003). www.genders.org.

Hirschauer, S. "The Manufacture of Bodies in Surgery." Social Studies of Science 21/2 (1991): 279-319.

Holmse, S., J.M. Kirk, M.O. Savage, and R.S. Kirby. "Surgical Reinforcement of Gender Identity in Adolescent Intersex Patients." Urologia Internationalis 48 (1992): 430-433.

Hutcheson, J. "Ambiguous Genitalia and Intersexuality." eMedicine Journal. www. emedicine.com/ped/topic1492.htm.

Intersex Society of North America. "Recommendations for Treatment." www.isna.org.

Kessler, S. and W. McKenna. Gender: An Ethnomethodological Approach. Chicago: University of Chicago Press, 1978.

Kipnis, K. and M. Diamond. "Pediatric Ethics and the Surgical Assignment of Sex." Journal of Clinical Ethics 9/4 (1998): 398-410.

Kroker, A. and M. Kroker, eds. Body Invaders: Panic Sex in America. New York: St. Martin's Press, 1987.

Kroker, A. and M. Kroker, eds. The Hysterical Male: New Feminist Theory. New York: St. Martin's Press, 1991.

Kroker, A. and M. Kroker, eds. The Last Sex: Feminism and Outlaw Bodies. New York: St. Martin's Press, 2001.

Lee, P., T. Mazur, R. Danish, J. Amrhein, R.M. Blizzard, J. Money, and C.L. Migeon. "Micropenis. 1. Criteria, Etiologies and Classification." Johns Hopkins Medical Journal 146 (1980): 156-163.

Marion, R. "The Curse of the Garcias." Discover (2000). www.discover.com/dec_00/ featvital_full.html.

May, B., M. Boyle, and D. Grant. "A Comparative Study of Sexual Experiences.” Journal of Health Psychology 1/4 (1996): 479-492.

McCullough, L. "The Ethics of Gender Reassignment." Presentation at 1999 Pediatric Gender Reassignment Conference: A Critical Reappraisal. Wyndham-Anatole Hotel, Dallas, TX, April 30, 1999. 
Meyer-Bahlburg, H.F.L. "Gender Identity Development in Intersex Patients." Child and Adolescent Psychiatric Clinic of North America 2 (1993): 501-512.

Meyer-Bahlburg, H.F.L. "Gender Assignment in Intersexuality.” Journal of the Psychology of Human Sex 10 (1998): 1-21.

Meyer-Bahlburg, H.F.L. "Gender and Sexuality in Classic Congenital Adrenal Hyperplasia." Endocrinology and Metabolism Clinics of North America 30/1 (2001): 155-171.

Meyer-Bahlburg, H.F.L. "Gender Assignment and Reassignment in Intersexuality: Controversies, Data, and Guidelines for Research." In Pediatric Gender Assignment: A Critical Reappraisal. Edited by S.A. Zderic, D.A. Canning, M.C. Carr, and H. Snyder. Dordrecht: Kluwer Academic/Plenum Publishers, 2002, pp. 199-223.

Meyers-Seifer, H. and N. Charest. "Diagnosis and Management of Patients with Ambiguous Genitalia." Seminars in Perinatology 16 (1992): 332-339.

Migeon, C., A. Wisniewski, and J. Gearhart. Syndromes of Abnormal Sex Differentiation: A Guide for Patients and Their Families. Baltimore: The Johns Hopkins Children's Center, 2001.

Money, J. "Psychological Counseling: Hermaphrodism." In Endocrine and Genetic Diseases of Childhood and Adolescence. Edited by L.I. Gardner. Philadelphia: W. B. Saunders, 1975.

Money, J. "Psychological Counseling: Hermaphroditism." In Endocrine and Genetic Diseases of Childhood and Adolescence. Edited by L. Gardner. Philadelphia: WB Saunders, 1975, pp. 609-618.

Money, J. Sex Errors of the Body and Related Syndromes: A Guide to Counseling Children, Adolescents, and Their Families, 2nd edn. Baltimore: Paul H. Brookes Publishing, 1994.

Money, J. and A. Ehrhardt. Man and Woman, Boy and Girl. Baltimore: The Johns Hopkins University Press, 1972.

Money, J., J.G. Hampson, and J.L. Hampson. "Hermaphroditism: Recommendations Concerning Assignment of Sex, Change of Sex, and Psychological Management." Bulletin of Johns Hopkins Hospital 97 (1955): 284-300.

Money, J., J.G. Hampson, and J.L. Hampson. "Imprinting and the Establishment of Gender Role." Archives of Neurology and Psychiatry 77 (1957): 333-336.

Natarajan, A. "Medical Ethics and Truth Telling in the Case of Androgen Insensitivity Syndrome." Canadian Medical Association Journal 154/4 (1996): 568-570.

Nussbaum, E. "A Question of Gender." Discover (2000). www.discover.com/jan_00/ featgender.html.

Oberfeld, S., A. Mondok, F Shahrivah, J.F. Klein, and L.S. Levine. "Clitoral Size in FullTerm Infants.” American Journal of Perinatology 6/4 (1989): 453-454.

Perelman, C. and L. Olbrechts-Tyteca. The New Rhetoric: A Treatise on Argumentation. Notre Dame: University of Notre Dame Press, 1969.

Peris, L. "Congenital Adrenal Hyperplasia Producing Female Hermaphroditism with Phallic Urethra." Obstetrics and Gynecology 16/2 (1960): 156-166.

Price, J. and M. Shildrick. Feminist Theory and the Body: A Reader. New York: Routledge, 1999.

Reiner, W. "Case Study: Sex Reassignment in a Teenage Girl." Journal of the American Academy of Child and Adolescent Psychiatry 35/6 (1996): 799-803.

Reiner, W. "Sex Assignment in the Neonate with Intersex or Inadequate Genitalia." Archives of Pediatrics and Adolescent Medicine 151/10 (1997): 1044-1045.

Riley, J. and C. Wodehouse. "Small Penis and the Male Sexual Role." Journal of Urology 142 (1989): 569-571. 
Rohatgi, M. “Intersex Disorders: An Approach to Surgical Management.” Indian Journal of Pediatrics 59 (1992): 523-530.

Rosenfield, R., A. Lucky, and T. Allen. "The Diagnosis and Treatment of Intersex." Current Problems in Pediatrics 10/7 (1980): 1-66.

Schildreck, M. Leaky Bodies and Boundaries: Feminism, Postmodernism and (Bio)ethics. London: Routledge, 1997.

Slijper, F.M.E. "Long-Term Psychological Evaluation of Intersex Children." Archive of Sexual Behavior 27/2 (1998): 125-144.

Slijper, F.M.E., S.L.S. Drop, J.C. Molenaar, and R. J. Scholtmaijer. "Neonates with Abnormal Genital Development Assigned the Female Sex: Parent Counseling." Journal of Sex Education and Therapy 20/1 (1994): 9-17.

Taha, S. "Male Pseudohermaphroditism: Factors Determining the Gender of Rearing in Saudi Arabia." Urology 43 (1994): 370-374.

Tiefer, L. "The Medicalization of Impotence - Normalizing Phallocentrism." Gender and Society 8/3 (1994): 363-377.

Van Seters, A.P. and A.K. Slob. "Mutually Gratifying Heterosexual Relationship with Micropenis of Husband." Journal of Sex and Marital Therapy 14/2 (1988): 98-107.

Wright, P. and A. Treacher, eds. The Problem of Medical Knowledge: Examining the Social Construction of Medicine. Edinburgh: Edinburgh University Press, 1982.

Yronwode, A. "Intersex Individuals Dispute Wisdom of Surgery on Infants." Synapse: University of California at San Francisco Medical School (UCSF campus weekly, March 11, 1999).

Interfakultäres Zentrum für Ethik in den Wissenschaften

Wilhelmstr. 19-23

D-72074 Tübingen

Germany

E-mail: David@ars.rhetorica.net 
